\title{
Effect of atenolol pre-treatment in heart damage in a model of intestinal ischemia-reperfusion ${ }^{1}$
}

Mieko Okada', Luiz Fernando Reis Falcão", David Ferez"I', José Luiz Martinsı , Paolo Ruggero Errantev Francisco Sandro Menezes Rodrigues ${ }^{v}$, Afonso Caricati-Neto ${ }^{\mathrm{VI}}$, Márcia MarinhovII, Guilherme FeneIon ${ }^{\mathrm{VIII}}$, Itamar Souza Oliveira-Júnior ${ }^{\mathrm{IX}}$

'Fellow PhD degree, Postgraduate Program in Translational Medicine, Universidade Federal de São Paulo (UNIFESP), Brazil. Acquisition, analysis and interpretation of data; technical procedures; statistical analysis, manuscript writing.

"PhD, Associate Professor, Division of Anesthesia, Pain and Intensive Medicine, Department of Surgery, UNIFESP, Sao Paulo-SP, Brazil. Interpretation of data, statistical analysis, manuscript writing, critical revision.

IIIPhD, Associate Professor, Division of Anesthesia, Pain and Intensive Medicine, Department of Surgery, UNIFESP, Sao Paulo-SP, Brazil. Interpretation of data, critical revision.

IVPhD, Full Professor, Division of Anesthesia, Pain and Intensive Medicine, Department of Surgery, UNIFESP, Sao Paulo-SP, Brazil. Interpretation of data, manuscript writing, critical revision.

VFellow PhD degree, Postgraduate Program in Pharmacology, UNIFESP, Sao Paulo-SP, Brazil. Histopathological examinations, analysis of data.

VIPhD, Associate Professor, Department of Pharmacology, UNIFESP, Sao Paulo-SP, Brazil. Manuscript writing, critical revision. VIIPhD, Full Professor, Veterinary Medicine School, UNESP, Araçatuba-SP, Brazil. Biochemistry data analysis, statistical analysis, critical revision.

VIIIAssociate Professor, Division of Cardiology, Department of Surgery, UNIFESP, Sao Paulo-SP, Brazil. Conception and design of the study, manuscript writing, critical revision.

${ }^{I X}$ Full Professor, Division of Anesthesia, Pain and Intensive Medicine, Department of Surgery, and Associate Professor, Postgraduate Program in Translational Medicine, UNIFESP, Sao Paulo-SP, Brazil. Conception and design of the study, critical revision, final approval of the version to be published.

\section{Abstract}

Purpose: To investigate the effects of atenolol in inflammatory mediator and oxidative stress in a myocardial injury by intestinal ischemia/reperfusion in rat model.

Methods: Adult Wistar male rats were randomly $(n=8)$, anesthetized and divided in: Sham: submitted to operation only; group SS+IR: intravenous saline infusion following superior mesenteric artery occlusion during 60 minutes (ischemia) and open for 120 minutes (reperfusion); group AT+IR: intravenous atenolol infusion (2 $\mathrm{mg} / \mathrm{kg}$ ) following superior mesenteric artery occlusion during 60 minutes (ischemia) and open for 120 minutes (reperfusion); and group $A T+I+A T+R$ : intravenous atenolol infusion following superior mesenteric artery occlusion during 60 minutes (ischemia) and in the time 45 minutes other atenolol doses were administrated and the artery was open for 120 minutes (reperfusion), all animals were submitted to muscular relaxation for mechanical ventilation. In the end of experiment the animals were euthanized and the hearts tissue were morphology analyzed by histology and malondialdehyde by ELISA, and the plasma were analyzed for tumor necrosis factor-alpha by ELISA.

Results: The group SS+IR demonstrated the higher malondialdehyde levels when compared with the atenolol treated-groups $(p=0.001)$ in the heart tissue. The tumor necrosis factoralpha level in plasma decrease in the treated groups when compared with SS+IR group $(p=0.001)$. Histology analyses demonstrate pyknosis, edema, cellular vacuolization, presence of inflammatory infiltrate and band contraction in the heart tissue of the rats.

Conclusion: Atenolol significantly reduce the degree of cardiac damage after intestinal ischemia-reperfusion.

Key words: Adrenergic Antagonists. Atenolol. Ischemia. Reperfusion. Cytokines. Oxidative Stress. Rats. 


\section{Introduction}

Ischemia and reperfusion (IR) injury of the intestine has been a significant health problem in terms of morbidity and mortality in many instances, such as abdominal aortic aneurysm surgery, intestinal transplantation, strangulated hernias, neonatal necrotizing enterocolitis, and other situations ${ }^{1}$. The intestinal IR can result in collapse of the systemic circulation (e.g., hypovolemic and septic shock) as well demonstrate ${ }^{2-5}$.

Intestinal IR damages the intestinal mucosal barrier and induces systemic inflammation through the endogenous generation of the oxygen-derived free radicals (OFRs), proinflammatory cytokines (e.g. TNFalpha), and a large amount of nitric oxide (NO) from inducible NO synthase(iNOS), thus, leading to the inflammatory injury and cell apoptosis ${ }^{5-7}$. The local and systemic inflammatory responses were caused by generation of a variety of proinflammatory mediators, such as TNF-alpha and oxygen free radicals in the circulation results in the systemic inflammatory response syndrome, one of major causes for morbidity and mortality during illness in general ${ }^{5,8}$.

Activated polymorphonuclear neutrophils (PMN) and proinflammatory cytokines are then released into the systemic circulation, interact with the vascular endothelium of distant organs, therefore, contributing to the systemic inflammatory response $e^{8,9}$.

Atenolol (an earlier-generation beta1-selective blocker) is an antihypertensive agent with cardiac selectivity offer theoretical advantages over non-selective drugs in patients with bronchial asthma, peripheral vascular disease ${ }^{10}$, decreased cardiac output, systolic and diastolic blood pressure, and reflex orthostatic hypotension ${ }^{11}$. Here we tested the hypothesis that treatment with AT would inhibit proinflammatory cytokine and diminish the production of oxygen free radicals in intestinal IR-induced heart injury in rats.

\section{Methods}

This study was approved by the Animal Experimentation Ethics Committee (CEUA - 5980160514), Universidade Federal de São Paulo (UNIFESP), complying with the guidelines of the Brazilian College of Animal Experimentation (COBEA).

Adult, male Wistar albino rats $(n=32)$ weighing between 260 and $310 \mathrm{~g}$, from the Center for Experimental Models Development in Medicine and Biology (UNIFESP) were used. Five animals per cage were kept with free access to filtered water and rodent chow (SuppraLab ${ }^{\circ}$, São Paulo, Brazil) under standard conditions of light (12/12 h dark cycle), humidity (45-55\%) and temperature $\left(25^{\circ} \mathrm{C}\right)$.

\section{Experimental design and Surgery}

After weighing, animals were anesthetized with a combination of xylazine (8-10 mg/kg; Ceva, São Paulo, Brazil) and ketamine (60-80 mg/kg; Cristália, São Paulo, Brazil) intramuscular injection the abdomen and groin were shaved and washed with $10 \%$ povidone iodine, intraperitonially injection at pancuronium (1 $\mathrm{mg} / \mathrm{kg}$ ) for muscle relaxation following mechanical ventilation (tidal volume, $5 \mathrm{~mL} / \mathrm{kg}$; positive end-expiratory pressure, 2 $\mathrm{CmH}_{2} \mathrm{O}$; fraction inspired of oxygen, $21 \%$ and respiratory rate, $60-70 \mathrm{ipm})$. The femoral vein was catheterized for fentanyl infusion $(2 \mu \mathrm{g} /$ $\mathrm{kg} / \mathrm{h}$ ). After confirmation of anesthetic plan, the midline laparotomy was performed and the superior mesenteric artery was identified, dissected and repaired, except in the Sham group. In all groups after mesenteric clamping the abdominal incision were then closed with 
2-0 suture, opened for clamp removal and closed again until the end of reperfusion (the intestinal tract was placed between gauze pads that had been soaked with warmed $0.9 \%$ $\mathrm{NaCl}$ solution). The occlusion of the superior mesenteric artery was confirmed by observing loss of pulsation of the mesenteric artery and its branches as well as paleness of the jejunum and ileum and the blood recirculation was performed with a clip removal (confirmed by observing the pulsation of the artery and its branches on the intestine).

The animals were divided ( $n=8 /$ group) in: Sham: operated only; SS+IR: intravenous saline solution for $\mathbf{3 0} \mathrm{min}$ following by superior mesenteric artery occluded for $60 \mathrm{~min}$ and 120 min of reperfusion; AT+IR: intravenous AT for $30 \mathrm{~min}$ following by superior mesenteric artery occluded for $60 \mathrm{~min}$ and $120 \mathrm{~min}$ of reperfusion; $A T+I+A T+R$ : intravenous $A T$ for 30 minutes following by superior mesenteric artery occluded for $60 \mathrm{~min}$, and in the time $30 \mathrm{~min}$ of ischemia other dose of AT was administered and 120 min of reperfusion.

\section{Atenolol protocol}

Atenolol (Sigma, São Paulo, Brazil; 2 $\mathrm{mg} / \mathrm{kg}$ ) solution was administered (by femoral vein) 30 minutes before ischemia (group AT+IR) or 30 minutes before and after ischemia (group $A T+I+A T+R)$.

\section{Cytokine analyses}

Blood sample of each animal was collected through cardiac puncture just before the sacrifice followed immediately by the centrifugation of the samples and stored at $-80^{\circ} \mathrm{C}$ until measurement of TNF-alpha. The detection of TNF-alpha in plasma of each animal was determined by the quantitative sandwich enzyme-linked immuno-sorbent assay techniques according to the manufacturer's instructions (Rat TNF- $\boldsymbol{\alpha}$ ELISA Kit ${ }^{\bullet}$, R\&D System, Minnesota, USA).

\section{Biochemical analyses}

In the end of experiment, after cardiac puncture, anesthetized animals were euthanatized by T-61 Euthanasia Solution (Schering-Plough, SP, Brazil) and the thoracotomy was performed and the heart was immediately removed and washing for removing the debris as well as the fat tissue around, the samples were divided for biochemical (stored at $-80^{\circ} \mathrm{C}$ ) and histological analyses.

After reperfusion, myocardial tissue was homogenized in ice-cold phosphate buffer to make a $10 \%$ homogenate. Then the homogenate was centrifuged at $3.000 \mathrm{rpm}$ for $15 \mathrm{~min}$.

\section{Malondialdehyde analyses}

The lipid peroxidation is used for a index of oxygen free radical production. The tissue samples were homogenized in $1 \mathrm{~mL}$ of $1.15 \%$ $\mathrm{KCl}$ (Synth, São Paulo, Brazil) with sonicator (Q700 ${ }^{\circ}$, QSonica, Connecticut, USA). The MDA content in cardiac tissue was measured using an OxiSelect ${ }^{\mathrm{TM}}$ MDA Adduct ELISA kit (Cell Biolabs, Inc., CA, USA) using a spectrophotometer (Genesys, Thermo Scientific, MA, USA) in absorbance at $450 \mathrm{~nm}$.

\section{Histologic evaluation}

The other part of heart was fixed in $10 \%$ formalin, embedded in paraffin, and sections of 4-5 $\mu \mathrm{m}$ were done. The slides were stained with hematoxylin and eosin (HE) and evaluated under an optical microscope (x400 and $\mathrm{x} 1.000$ ) (Zeiss Axion Image $\mathrm{A} 2^{\circ}$, Oberkochen, Germany) by an experienced pathologist blinded, descriptive analysis, to the 
different groups. On histologic examination, the myocardium lesions were classified according to the presence of: hyperemic blood vessels, pyknosis, inflammatory infiltration, cardiomyocytes degeneration, loss of striation and interstitial edema.

The score for cardiac damage analysis was adapted from Aneja et al. ${ }^{12}$ : $0=$ is no damage; 1 (mild)= hyperemic blood vessels, pyknosis; 2 (moderate) $=$ hyperemic blood vessels, pyknosis and inflammatory infiltration; 3 (severe)= hyperemic blood vessels, pyknosis, inflammatory infiltration and cardiomyocytes degeneration; 4 (highly severe)= the same condition of score 3 with loss of striation.

\section{Statistical analysis}

Histological sections were interpreted by professionals blinded to the group and timing of the experiments. Quantitative data were summarized as means and standard deviations ( $\mathrm{m} \pm \mathrm{SD}$ ) and compared using oneway analysis-of variance (ANOVA) using a SPSS software 13.0 (SPSS Inc., IL, USA). $P<0.05$ were considered statistically significant.

\section{- Results}

All animals survived during the total time of experiment. The MDA content (Figure 1) of heart samples from Sham $(2.43 \pm 0.28$ $\mathrm{pmol} / \mathrm{mg}$ ) animals was statically significant when compared with all others groups $(P=$ $0.001)$. The level of MDA in group SS+IR (8.0 $\pm 0.37 \mathrm{pmol} / \mathrm{mg}$ ) was higher when compared with the treated groups. On the other hand, average MDA contents of tissues from AT+IR (5.6 $\pm 0.35 \mathrm{pmol} / \mathrm{mg}$ ) and $A T+\mathrm{I}+\mathrm{AT}+\mathrm{R}$ (5.15 $\pm 0.49 \mathrm{pmol} / \mathrm{mg})$ groups were statistically different $(P<0.05)$.

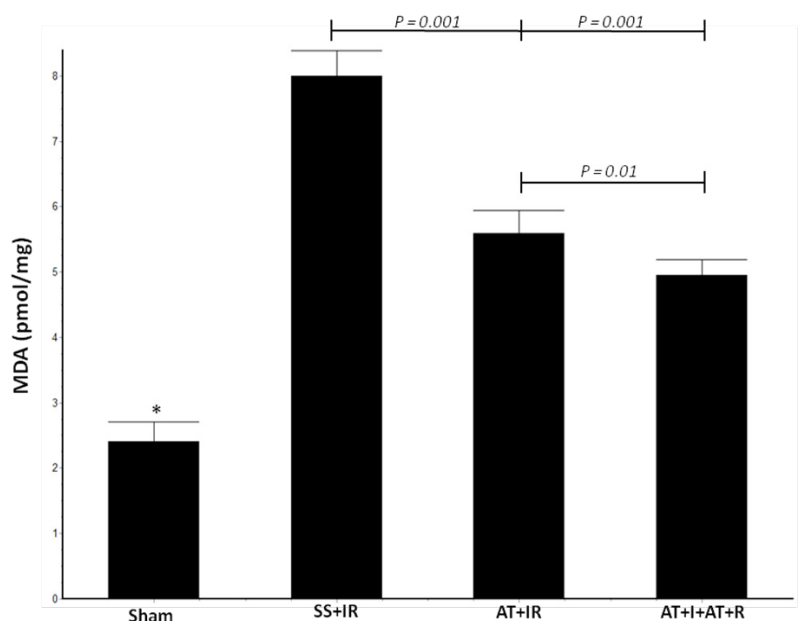

Figure 1 - Effect of AT on tissue MDA level after intestinal IR. Average MDA level of tissue samples collected from sham operated control, IR control, $A T+I R$, and $A T+I+A T+R$ groups. Data are expressed as the mean \pm standard deviation of the mean $(p<$ 0.05, ANOVA, Tukey post hoc.).

TNF-alpha level (Figure 2) in the plasma samples from Sham $(87.75 \pm 5.339 \mathrm{pg} / \mathrm{mL}$ ) group was statistical significant when compared with all others group $(P=0.001)$. In the group SS+IR $(288.37 \pm 10.04 \mathrm{pg} / \mathrm{mL})$ the TNF-alpha was increased when compared with $A T+I R$ $(226.50 \pm 26.19 \mathrm{pg} / \mathrm{mL})$ group $(P=0.001)$ and AT+I+AT+R (194.25 $\pm 32.60 \mathrm{pg} / \mathrm{mL})$ group $(P=$ $0.001)$. The statistical difference was observed between AT+IR and AT+I+AT+R $(P<0.05)$.

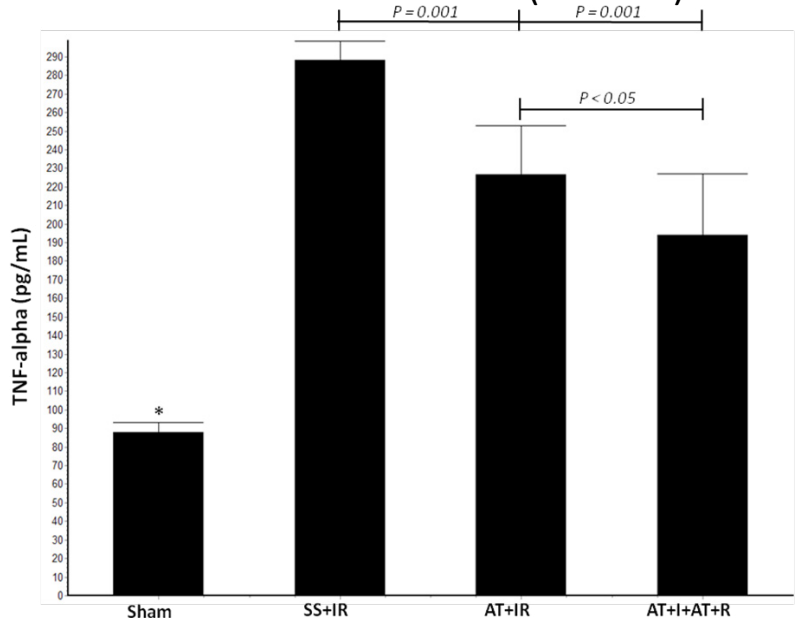

Figure 2 - Effect of AT on plasma TNF-alpha level after intestinal IR. Average TNF-alpha level of plasma samples collected from sham operated control, IR control, AT+IR, and AT+I+AT+R groups. Data are expressed as the mean \pm standard deviation of the mean ( $p<0.05$, ANOVA, Tukey post hoc.). 
The histological analysis was performed using the cardiac tissue from each group and the description made by two pathologists who were unaware groups to which the samples belong. The most several alterations were observed in the SS+IR, interstitial edema, hyperemic blood vessels, pyknosis, inflammatory infiltration and derangement of myocardium fibers. In the Sham group, normal configuration was evident. Pretreatment with one and two AT doses resulted in reduction of damage (Figures 3 and 4). The score of cardiac tissue damage (Figure 5) was significant when compared the group SS+IR $(3.85 \pm 0.35)$ with the treated groups $(P=0.001)$.

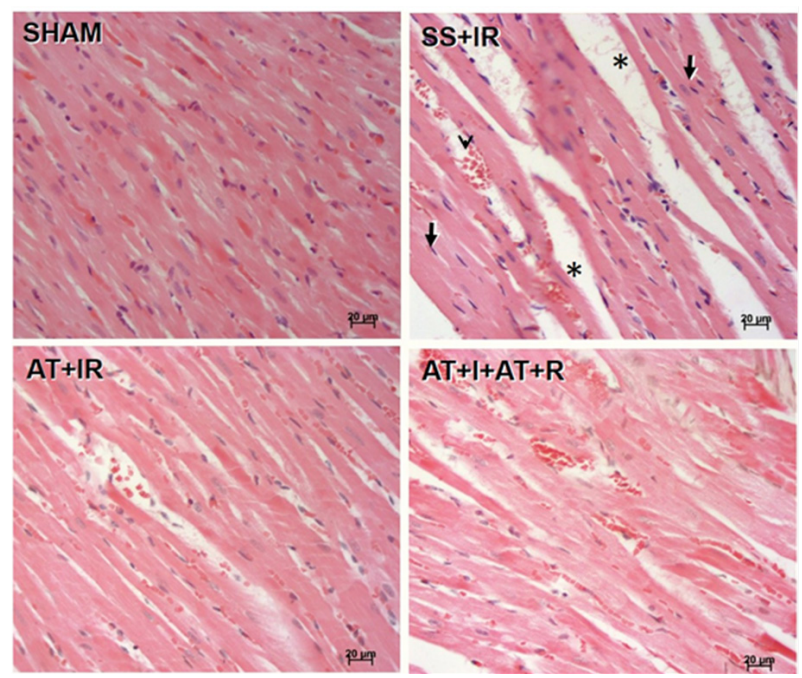

Figure 3 - Photomicrographs of the cardiac tissue from Sham, saline solution and ischemiareperfusion (SS+IR), and atenolol treated groups $(A T+I R$ and $A T+I+A T+R)$. Observe in $S S+I R$ group the damage tissue with derangement of myocardium fibers and band contraction, dispersed pyknotic nucleus (arrows), hyperemic blood vessels (arrowhead), and interstitial edema $\left(^{*}\right)$. In pretreated groups (AT+IR and $A T+I+A T+R)$ this effects were diminished. $\mathrm{HE}, \mathrm{x} 400$.
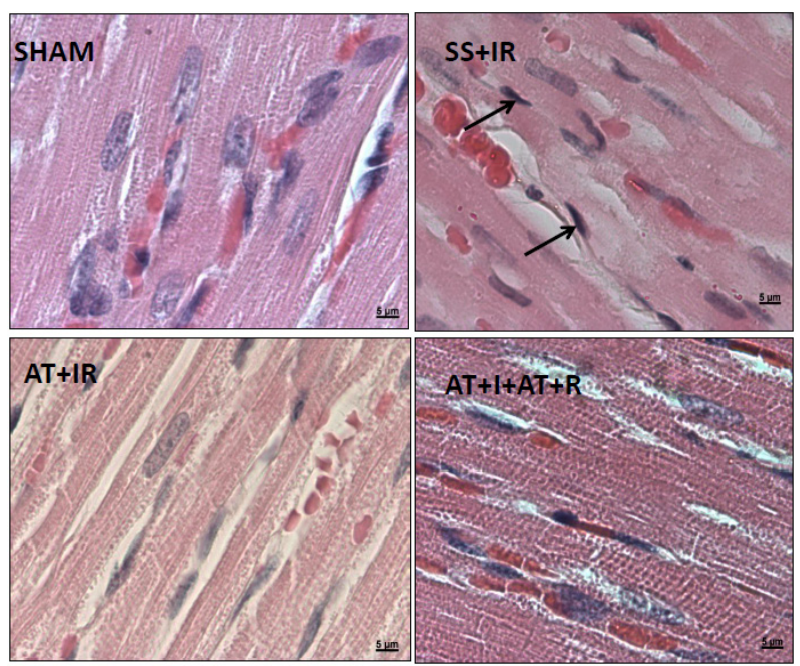

Figure 4 - Photomicrographs of the cardiac tissue from Sham, saline solution infusion and ischemiareperfusion (SS+IR), and atenolol pretreated groups $(A T+I R$ and $A T+I+A T+R)$. Observe in $S S+I R$ group the presence at pyknotic nucleus (arrows), degeneration of cardiomyocytes evidenced by loss of striations and no presence of this alterations in the treated groups. $\mathrm{HE}, \mathrm{x} 1.000$.

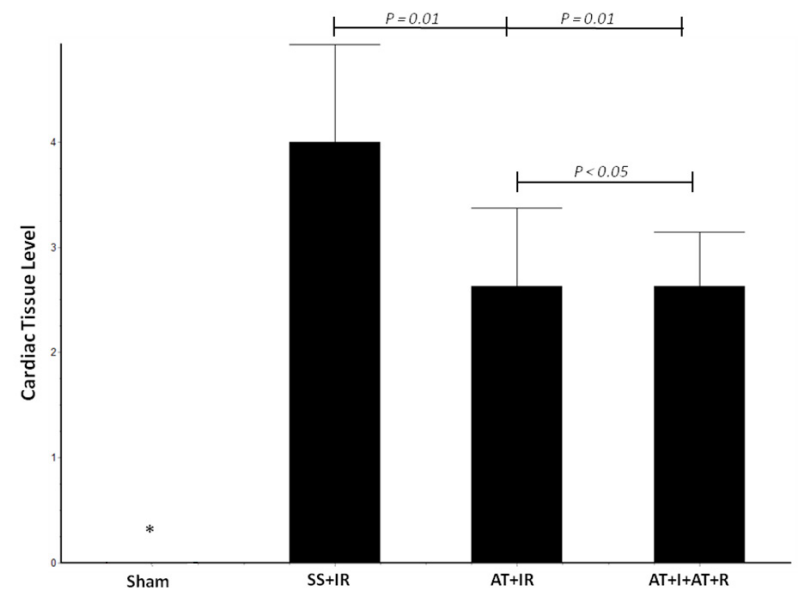

Figure $\mathbf{5}$ - The cardiac tissue injury scores in rats submitted to intestinal ischemia-reperfusion (IR) associated or not to the treatment with atenolol (AT), according to the morphological evaluation. Data are expressed as the mean \pm standard deviation of the mean $(p<0.05$, ANOVA, Tukey post hoc.). 


\section{- Discussion}

The present work showed in an acute rat model of intestinal ischemia-reperfusion that administration of AT before ischemia and during reperfusion protects the heart against systemic inflammation by the generation of the oxygen-derived free radicals and TNFalpha and all animals survived at the end of experiment.

The phenomenon of intestinal ischemia and reperfusion is a frequent event in the clinic and is associated with deleterious effects on the distance organs, especially the heart. The IR, and consequent oxidative stress is associated with medical and surgical conditions such as: sepsis, arterial occlusive trauma, cardiac arrest, thrombosis, embolism, vasospasm, transplantation and resection of organs and myocardial infarction ${ }^{13}$.

Intestinal ischemia followed by reperfusion is closely related to the generation and modulation of reactive oxygen species phenomenon. Local changes in the gut promote humoral and cellular responses that, spread into the bloodstream, affect the homeostasis by inducing cardiac tissue related responses with generation of the oxygen-derived free radicals ${ }^{1,14-17}$. Inflammatory cells and free radicals have been shown to contribute to cardiac dysfunction caused by intestinal ischemia-reperfusion injury ${ }^{18,19}$.

Malondialdehyde (MDA), the product of lipid peroxidation, is a good marker of free radical-mediated damage and oxidative stress. Increased levels of lipidic peroxidation products, by measurement of MDA, have been associated with various conditions and pathological states of diseases, including states of ischemia and reperfusion. The increases of oxygen inside cells favor the production of free radicals, causing damage in biological membranes rich in lipids ${ }^{19}$.

We observed in our study, the MDA content of heart samples from Sham animals was statically significant when compared with all others groups, and level of MDA in group SS+IR was higher when compared with the treated groups.

The NADPH oxidase is a group of enzymes with oxidase intracellular expression, perinuclear and present in many tissues, and their presence in significant cardiovascular tissue ${ }^{20}$. This system is involved in the production of reactive oxygen species, vasomotor control and apoptosis. Inflammatory cytokines, including TNF-alpha, act as modulators of gene expression of NADPH system ${ }^{21}$.

In our study, TNF-alpha level in the plasma of pre-treated groups, were decreased when compared with $\mathrm{SS}+\mathrm{IR}$, and statistical difference was observed between $A T+I R$ and $A T+1+A T+R$ groups. The TNF-alpha derived from macrophages can be interacting with endothelial cells, inducing the expression of adhesion molecules ICAM-1, VCAM- 1 and E-selectin, permitting the access of leukocytes in inflammatory focus, favoring adherence, chemotaxis, degranulation and oxidative burst ${ }^{22}$. Previous reports demonstrated the importance of TNF-alpha in lesions and lethality associated with ischemia and reperfusion, evaluated local and systemic lesions, and the use of strategies to diminish TNF-alpha production are associated with reduction of lethality ${ }^{23}$.

In relation to intestine lesion, besides local tissue damage, occurs the risk of systemic compromise by the amplification of process to distant organs, e.g. heart ${ }^{24,25}$. This hypothesis can be reinforce by the histological analysis of heart, where most several alterations were observed in the SS+IR group. Intestinal ischemia active sympatric nervous system, can be resulting increase of arterial blood pressure ${ }^{26}$, with more blood inside heart, making the myocardium muscle work with more power to eject this blood to the rest of body, with 
increase of intracellular calcium, oxygen and metabolites. Theses intracellular products can be response with dysfunction in myocardial contraction and relaxation, a consequence of intestinal ischemia-reperfusion in experimental animals $^{19,27}$.

The actions of beta-blocker were different in the lipophilicity, cardioselectivity, and vasodilatation. Drugs, such as carvedilol, metoprolol and labetalol are lipid solubility and have peripheral vasodilators effects; other drugs, such atenolol and practolol are not lipid solubility and not have peripheral vasodilator effects, moreover possess cardiac selectivity ${ }^{10,28,29}$.

Earlier studies have shown that carvedilol, a beta-blocker commonly used to treat cardiovascular diseases, such as hypertension, prevents lipid peroxidation and depletion of endogenous antioxidants ${ }^{28}$.

Atenolol, a beta-1-selective blocker, is implicating with cross-talk between adrenoceptors and adenosine receptors to promote cardioprotection and other cytoprotective effects ${ }^{29}$. Campos et al. ${ }^{30}$ where AT attenuated the motor and neural dysfunctions in rat small bowel caused by ischemia-reperfusion.

Ischemia-reperfusion injury of the gastrointestinal tract not only causes local damage, but may also be a factor in the development of multiple organ dysfunction syndrome associated with reperfusion injury, and atenolol, probably cause inference in adenosine receptors to promote local and systemic cytoprotection ${ }^{30}$. In our experiments, the heart injury was distally induced, by intestinal IR, as well the preventive action, by AT infusion.

The extrapolation the cardiac dysfunction in a rat model of intestinal IR to the human patients is necessary extreme caution, because was expected, in humans, to reduce diastolic filling and ejection fraction when exist intestinal hypoperfusion. In this context, the study of new pharmacological interventions is very important to reduce organic lesions caused by intestinal ischemia and reperfusion, with important repercussion in mortality of patients.

\section{Conclusion}

The treatment with atenolol attenuated the cardiac dysfunctions in rat small bowel caused by ischemia-reperfusion.

\section{- References}

1. Stallion A, Kou TD, Latifi SQ, Miller KA, Dahms BB, Dudgeon DL, Levine AD. Ischemia/reperfusion, a clinically relevant model of intestinal injury yielding systemic inflammation. J Pediatr Surg. 2005;40:4707. doi: 10.1016/j.jpedsurg.2004.11.045.

2. Mallick IH, Yang W, Winslet MC, Seifalian AM. Ischemia-reperfusion injury of the intestine and protective strategies against injury. Dig Dis Sci. 2004;49:1359-77. PMID: 15481305.

3. Sato Y, Itagaki S, Oikawa S, Ogura J, Kobayashi M, Hirano T, Sugawara M, Iseki K. Protective effect of soy isoflavone genistein on ischemia-reperfusion in the rat small intestine. Biol Pharm Bull. 2011;34:1448-54. PMID: 21881232.

4. Wen SH, Li Y, Li C, Xia ZQ, Liu WF, Zhang $X Y$, Lei WL, Huang WQ, Liu KX. Ischemic postconditioning during reperfusion attenuates intestinal injury and mucosal cell apoptosis by inhibiting Jak/STAT signaling activation. Shock. 2012;38:411-9. doi: 10.1097/SHK.0b013e3182662266.

5. Zhang $F$, Tong L, Qiao $H$, Dong $X$, Qiao $G$, Jiang $H$, Sun $X$. Taurine attenuates multiple organ injury induced by intestinal ischemia reperfusion in rats. J Surg Res. 2008;149(1):101-9. doi: 10.1016/j. jss.2007.12.781.

6. Cámara-Lemarroy CR, Guzmán-de la Garza FJ, Alarcón-Galván G, Fernández-Garza NE. The effects of NMDA receptor antagonists over intestinal ischemia/reperfusion injury in rats. Eur J Pharmacol. 2009;621(1-3):78- 
85. doi: 10.1016/j.ejphar.2009.08.038.

7. Takeshita M1, Tani T, Harada S, Hayashi H, Itoh H, Tajima H, Ohnishi I, Takamura H, Fushida S, Kayahara M. Role of transcription factors in small intestinal ischemiareperfusion injury and tolerance induced by ischemic preconditioning. Transpl Proc. 2010;42:3406-13. doi: 10.1016/j. transproceed.2010.06.038.

8. Aprahamian CJ, Lorenz RG, Harmon CM, Dimmit RA. Toll-like receptor 2 is protective of ischemia-reperfusion mediated smallbowel injury in a murine model. Pediatr Crit Care Med. 2008;9:105-9. PMID: 17906593.

9. Tian XF, Yao JH, Li YH, Zhang XS, Feng BA, Yang CM, Zheng SS. Effect of nuclear factor kappa $B$ on intercellular adhesion molecule-1 expression and neutrophil infiltration in lung injury induced by intestinal ischemia/ reperfusion in rats. World J Gastroenterol. 2006;12:388-92. doi: 10.3748/WJG.v12. i3.388.

10.Barnett MJ, Milavetz G, Kaboli PJ. betaBlocker therapy in veterans with asthma or chronic obstructive pulmonary disease. Pharmacotherapy. 2005;25(11):1550-9. PMID: 16232018.

11.Machackova J, Sanganalmath SK, Barta J, Dhalla KS, Dhalla NS. Amelioration of cardiac remodeling in congestive heart failure by beta-adrenoceptor blockade is associated with depression in sympathetic activity. Cardiovasc Toxicol. 2010;10:9-16. doi: 10.1007/s12012-009-9058-y.

12.Aneja R, Hake PW, Burroughs TJ, Denenberg AG, Wong HR, Zingarelli B. Epigallocatechin, a green tea polyphenol, attenuates myocardial ischemia reperfusion injury in rats. Mol Med. 2004;10(1-6):55-62. PMID: 15502883.

13. Weil MH, Becker LB, Bundinger T. Workshop executive summary report, postresuscitative and initial utility in life saving efforts (PULSE). Circulation. 2001;103:1182-4. PMID: 11238256.

14.Bolli R, Jeroudi MO, Patel BS. Direct evidence that oxygen-derived free radicals contribute to postischemic myocardial dysfunction in the intact dog. Proc Natl Acad Sci USA. 1989;86:4695-9. PMID: 2543984.

15.Carden DL, Granger DN. Pathophysiology of Ischemia-reperfusion injury. J Pathol. 2000;190:255-66. PMID: 10685060.
16.Kloner RA, Przyklenk K, Campbell CA. Coronary reperfusion following experimental myocardial infarction. J Card Surg. 1987;2:291-7. PMID: 2979979.

17.Zweier JL, Flaherty JT, Weisfeldt M. Direct measurement of free radical generation following reperfusion of ischemic myocardium. Proc Natl Acad Sci USA. 1987;84:1404-7. PMID: 3029779.

18. Ferdinandy P, Danial H, Ambrus I, Rothery RA, Schulz R. Peroxynitrite is a major contributor to cytokine-induced myocardial contractile failure. Circ Res. 2000;87:241-7. PMID: 10926876.

19. Horton JW, White DJ. Free-radical scavengers prevent intestinal ischemia-reperfusionmediated cardiac dysfunction. J Surg Res. 1993;55(3):282-9. PMID: 8412111.

20.Ayala A, Muñoz MF, Argüelles S. Lipid peroxidation: production, metabolism, and signaling mechanisms of malondialdehyde and 4-hydroxy-2-nonenal. Oxid Med Cell Longev. 2014;2014:360438. doi: $10.1155 / 2014 / 360438$.

21.Chen F, Haigh S, Barman S, Fulton DJ. From form to function: the role of Nox4 in the cardiovascular system. Front Physiol. 2012;3:412. PMID: 23125837.

22.Basuroy S, Bhattacharya S, Leffler CW, Parfenova H. Nox4 NADPH oxidase mediates oxidative stress and apoptosis caused by TNFalpha in cerebral vascular endothelial cells. Am J Physiol Cell Physiol. 2009;296(3):C42232. doi: 10.1152/ajpcell.00381.2008.

23. Hehlgans T, Pfeffer K. The intriguing biology of the tumor necrosis factor/tumor necrosis factor receptor superfamily: players, rules and the games. Immunology. 2005;115(1):120. PMID: 15819693.

24.Souza DG, Teixeira MM. The balance between the production of tumor necrosis factor-alpha and interleukin-10 determines tissue injury and lethality during intestinal ischemia and reperfusion. Mem Inst Oswaldo Cruz. 2005;100(S1):59-66. PMID: 15962100.

25.Swank GM, Deitch EA. Role of the gut in multiple organ failure, bacterial translocation and permeability changes. World J Surg. 1996; 20:411-7. PMID: 8662128.

26.Varga J, Tóth $S$, Staško $P$, Tóth $S \mathrm{Jr}$, Bilecová-Rabajdová $M$, Ostró $A$, Veselá J. Intestinal ischemia-reperfusion injury 
- the histopathological status of remote vital organs in acute and subacute phases. Ann Transplant. 2012;17(1):11-20. PMID: 22466904.

27.Cividjian A, Rentero N, Quintin L. Reduced blood pressure lability during emergence from anaesthesia in rats: a pilot study using clonidine. Acta Anaesthesiol Scand. 2008;52(2):295-301. PMID: 17995999.

28.Christopher TA, Lopez BL, Yue TL, Feuerstein GZ, Ruffolo RR Jr, Ma XL. Carvedilol, a new beta-adrenoreceptor blocker, vasodilator and free-radical scavenger, exerts an antishock and endothelial protective effect in rat splanchnic ischemia and reperfusion. J Pharmacol Exp Ther. 1995;273(1):64-71. PMID: 7714814.

29.Asanuma $H$, Minamino $T$, Sanada $S$, Takashima S, Ogita H, Ogai A, Asakura M, Liao Y, Asano Y, Shintani Y, Kim J, Shinozaki Y, Mori H, Node K, Kitamura S, Tomoike H,
Hori M, Kitakaze M. Beta-Adrenoceptor blocker carvedilol provides cardioprotection via an adenosine dependent mechanism in ischemic canine hearts. Circulation. 2004;109(22):2773-9. PMID: 15148268.

30.Campos VF, Miranda-Ferreira R, Taha NS, Teixeira GD, Souza WT, Carmo CE, Silva-Neto LA, Gomes IT, Monteiro HP, Montero EF, Fagundes DJ, Caricati-Neto A, Taha MO. Atenolol to treat intestinal ischemia and reperfusion in rats. Transplant Proc. 2012;44(8):2313-6. doi: 10.1016/j. transproceed.2012.07.058.

\section{Acknowledgements}

To Prof. Dr. Manuel de Jesus Simões and Kátia de Vasconcelos for their technical support during the histological procedures.

\section{Correspondence:}

Itamar Souza Oliveira-Junior

Rua Napoleão de Barros, $715 / 5^{\circ}$ andar

04024-002 São Paulo - SP Brasil

Tel.: (55 11)5576-4069 / 55712746

souza.oliveira@unifesp.br

Received: July 16, 2017

Review: Sept 19, 2017

Accepted: Oct 22, 2017
Conflict of interest: none

Financial source: FAPESP

${ }^{1}$ Research performed at Laboratory of Experimental Surgery, and Laboratory of Pharmacology, Universidade Federal de São Paulo (UNIFESP), Brazil. Part of PhD degree thesis, Postgraduate Program in Translational Medicine. Tutor: Itamar Souza de Oliveira Junior. 